\title{
Electrophysiological studies of peripheral nerves in patients with organic mercury poisoning
}

\author{
PAMELA M. LE QUESNE, ${ }^{1}$ S. F. DAMLUJI, AND H. RUSTAM \\ From the Departments of Medicine and Neurology, Medical College, Baghdad; \\ M.R.C. Toxicology Unit, Carshalton, Surrey; and the Department of Neurological Studies, \\ The Middlesex Hospital, London
}

SYNOPSIS Nineteen patients with organic mercury poisoning were examined clinically and electrophysiological studies were carried out on their peripheral nerves. Four severely affected patients were disorientated, restless, and unable to speak. Vision was abnormal in nearly half the patients, usually consisting of gross constriction of visual fields with preservation of central acuity. Severe cerebellar abnormalities were present in most. Paraesthesiae were common. On sensory examination, all except three patients had one or more of the following abnormalities: reduced appreciation of pin prick peripherally, defective position sensation, abnormal two-point discrimination, astereognosis. Vibration sensation was normal in all. Despite these sensory findings no electrophysiological abnormality was demonstrated in the peripheral nerves. It is suggested that the sensory disturbances are predominantly or entirely due to damage to the central nervous system.

The classical features of organic mercury poisoning were first described by Hunter et al. in 1940 and subsequently seen in many other patients, particularly after two episodes of poisoning in Japan at Minamata and Nigata. Further outbreaks of poisoning occurred in Iraq in 1956 and 1960 as a result of eating wheat seed treated with organic mercurial fungicide (Jalili and Abbasi, 1961 ; Damluji, 1962).

The clinical features of patients affected by organic mercury in these various episodes have been similar. Dysarthria, ataxia, and concentric constriction of the visual fields with preserved acuity for central vision were characteristic. Sensory disturbances were common. The initial symptoms were usually paraesthesiae and numbness around the mouth and in the hands and feet. Three of the four patients described by Hunter et al. (1940) had gross position sense loss, astereognosis, and impaired two point discrimination, but vibration sense was impaired only in one. Other modalities of superficial sensation were normal in all. They suggested that

\footnotetext{
1 Requests for reprints: Dr. P. M. Le Quesne, The Middlesex Hospital, London, WIN 8AA.
}

the sensory abnormalities were due to peripheral neuropathy followed by degeneration of the posterior columns. This appeared to be confirmed by their findings of marked Walleriantype degeneration of sensory nerves in rats poisoned by organic mercury.

More recent studies have confirmed that in rats the earliest detectable pathological change occurs in sensory peripheral nerves (Miyakawa et al., 1970). Cavanagh and Chen (1971) found degeneration of primary sensory neurones of dorsal root and trigeminal ganglia causing whole cell or whole fibre death at a time when only minor changes were present in the cerebellum and none detectable elsewhere in the nervous system.

Less detailed studies have been carried out in other species. Non-primates that have been studied include ferrets (Hanko et al., 1970), pheasants and hens (Borg et al., 1969), and goshawks (Borg et al., 1970). Peripheral nerve degeneration has been described in all of them. However, although only limited observations are available in primates, it is possible that peripheral nerves are less susceptible. Hunter et al. 
(1940) studied one monkey in which marked ataxia was produced by exposure to fumes of methyl mercury iodide. They described focal degeneration of myelin sheaths in peripheral nerves, but without the severe Wallerian-type degeneration seen in rats. No abnormality was detected in the spinal cord. Nordberg, Berlin, and Grant are quoted in the Report from an Expert Group on Methyl Mercury in Fish (1971) as having found no abnormality of peripheral nerves in the squirrel monkey after dosing with methyl mercury dicyandiamide.

Pathological studies in man also suggest that peripheral nerves may escape gross damage. A necropsy was performed on one of the original patients of Hunter et al. (1940), 15 years after the acute episode (Hunter and Russell, 1954). No abnormality was detected in the spinal cord, nerve roots, posterior root ganglia, sciatic, or ulnar nerves. Takeuchi (1968) has described pathological findings in 17 of the adult Minamata cases. No gross changes were found in either the spinal cord or peripheral nerves, and he writes that 'granular degeneration of the myelin and localized demyelination were found on rare occasions'. The Report from an Expert Group on Methyl Mercury in Fish (1971) concludes that 'there is suggestive but no definite information about damage to the peripheral nerves, a regrettable gap in our knowledge considering the clinical manifestations in human beings and the distinct changes in experimental meHg poisoning in animals'.

After their pathological study, Hunter and Russell (1954) suggested that early sensory loss was due to reversible peripheral neuropathy. They thought that the post-central cortical lesions were probably too slight to account for the findings. Shiraki and Takeuchi (1971) have also suggested that paraesthesiae and superficial sensory loss may be due to reversible peripheral neuropathy, but that the abnormalities of deep sensation are probably the result of post-cerebral cortical lesions. Tokuomi (1968) attributed all the sensory abnormalities to peripheral neuropathy. Snyder (1972) also implied that the sensory disturbances and possibly some of the ataxia were due to peripheral neuropathy. The Swedish Report of an Expert Group on Methyl Mercury in Fish (1971) comments that 'clinically, there are signs of peripheral nerve involve- ment in human beings but no clear-cut pathological confirmation as yet. Damage to sensory nerves, however, has been demonstrated in some experimental studies'. Clearly, there is consider- قิ able confusion and doubt as to the anatomical 0 basis for the sensory disturbance in man.

An opportunity has recently arisen to investigate a group of patients poisoned with methyl mercury as a result of eating wheat dressed with a fungicide (Damluji and Tikriti, 1972). A preliminary report of this outbreak has been published by Bakir et al. (1973). Electrophysiological studies have been carried out on the peripheral nerves of 19 of these patients and correlated with the clinical neurological abnormalities.

\section{METHODS}

CLINICAL FEATURES Nineteen patients suffering from methyl mercury poisoning were examined while $\omega_{y}$ hospital inpatients in Medical City, Baghdad. Theino $\omega$ ages ranged from 5 to 55 years (Table 1). All ha $\bar{\phi} \underset{\omega}{\omega}$ eaten methyl mercury contaminated wheat for $\$$ period of about six weeks at the end of 1971. Ther胥 was then a latent interval of between two and threeweeks before they developed symptoms, which pros gressed for a few weeks. The present studies were carried out about four months after the onset of. symptoms.

TABLE 1

AGE DISTRIBUTION OF PATIENTS

\begin{tabular}{cc}
$\begin{array}{c}\text { Age } \\
\text { (yr) }\end{array}$ & $\begin{array}{c}\text { Patients } \\
\text { (no.) }\end{array}$ \\
\hline $0-9$ & 3 \\
$10-19$ & 8 \\
$20-29$ & 3 \\
$30-39$ & 2 \\
$40-49$ & 1 \\
$50-59$ & 2 \\
\hline
\end{tabular}

Four patients showed severe mental changes, being unaware of their surroundings, unable to speak, and incontinent. Myoclonic jerks, particularly affecting the neck and shoulder were present in two. Three of them were restless with intermittent rigidity which appeared to be voluntarily determined. They had no limb weakness. The fourth patient had spastic, flexed limbs with little spontaneous movement. Three of the four patients had increased tendon 
reflexes and extensor plantar responses. The remaining 15 patients were fully alert and orientated.

The incidence of visual abnormalities is shown in Table 2. Vision was normal in six patients; it could not be assessed in the four confused patients described above or in one other child. Definite abnormalities were present in eight of the remaining patients. In one patient acuity was reduced to the appreciation of light only. In seven, visual fields were grossly constricted when tested on confrontation. This was confirmed on testing with an Amsler chart in three in whom vision was reduced to less than $5^{\circ}$ from the fixation point. Central visual acuity appeared normal in these seven patients. Four of them were tested on a Snellen scale, revealing acuity of $6 / 6$ in each eye in three and 6/9 in the fourth patient. There was no evidence that vision had changed in any of these patients since the onset of symptoms. Fundi and pupillary reactions were normal in all instances.

TABLE 2

VISUAL ABNORMALITIES

\begin{tabular}{lc}
\hline & $\begin{array}{c}\text { Patients } \\
\text { (no.) }\end{array}$ \\
\hline Light appreciation only & 1 \\
Constricted fields & 7 \\
Untestable & 5 \\
None & 6 \\
\hline
\end{tabular}

Other cranial nerve abnormalities were present in three patients. One had bilateral external rectus weakness. Another had mild bilateral ptosis, unequal pupils, and poor pupillary reaction to light. A slight upper motor neurone facial weakness was present in one patient.

There was no limb or trunk weakness or wasting. One patient was areflexic. The relation of this to mercury poisoning is doubtful, because, although heavily exposed, his only symptoms were of limb pains and he had no other abnormal neurological signs. Arm reflexes were sluggish but present in seven others. In the mentally alert patients tendon reflexes were otherwise normal, but one had extensor plantar responses.

The commonest and most disabling abnormality was of cerebellar function. The incidence and severity is shown in Table 3. Excluding the four patients with severe mental changes, inability to walk was entirely due to cerebellar disorder. Gross slurring dysarthria was present in those with severe
TABLE 3

DEGREE OF CEREBELLAR INVOLVEMENT

\begin{tabular}{ll}
\hline & $\begin{array}{c}\text { Patients } \\
\text { (no.) }\end{array}$ \\
\hline Past history of inability to walk, & 15 \\
even with assistance & \\
Present signs: & 4 \\
Severe mental changes & 6 \\
Unable to walk unaided & 5 \\
Unable to walk heel to toe & 2 \\
Mildly ataxic gait & 2 \\
None & \\
\hline
\end{tabular}

ataxia. No patient had nystagmus. From the histories it appeared that there had been some improvement in ataxia for about four weeks before they were examined by the authors. Only one patient was still unable to walk even with assistance, whereas nearly all had been unable to do so when at their worst. This patient subsequently improved to the extent that she could walk without assistance.

Details of sensory symptoms and signs are shown in Table 4. Four of the 19 patients had no sensory symptoms. Among the remainder paraesthesiae were the commonest initial complaints, affecting the hands and feet and also prominent around and inside the mouth and on the tongue.

TABLE 4

SYMPTOMS AND SIGNS OF SENSORY INVOLVEMENT*

\begin{tabular}{crll}
\multicolumn{1}{c}{ Symptoms } & \multicolumn{2}{c}{ Present signs } \\
\hline $\begin{array}{c}\text { Past history } \\
\text { Paraesthesiae }\end{array}$ & 11 & Severe mental changes & 4 \\
Numbness & 3 & $\begin{array}{l}\text { Superficial disturbances } \\
\text { Position sense loss }\end{array}$ & 5 \\
None & 4 & $\begin{array}{l}\text { Defective 2-point } \\
\text { discrimination }\end{array}$ & 4 \\
$\begin{array}{c}\text { Present symptoms } \\
\text { Severe mental } \\
\text { changes }\end{array}$ & 4 & $\begin{array}{l}\text { Astereognosis } \\
\text { None }\end{array}$ & 6 \\
Paraesthesiae & 6 & & 6 \\
Numbness & 2 & & \\
\hline
\end{tabular}

* One child omitted whose history and sensory signs could not be evaluated.

On examination superficial sensory disturbances in a glove and stocking distribution were present in five, in three of them extending as high as elbows and knees. The abnormalities were not severe, and consisted only of subjective blunting to pin prick. In only one patient was appreciation of light touch 
defective in the affected areas. Temperature sensation was normal in all.

Position sense for fine movements was defective in the fingers and toes in four patients, but in all of them large movements of the digits were appreciated and position sense was normal at proximal joints. Vibration sensation was normal at the fingers and toes in all patients. Two-point discrimination on the index finger was defective in five patients, so that no threshold could be obtained. Six patients, mostly children, were unable to understand the test.

The most interesting sensory finding was astereognosis, which was marked in six patients. It was the only sensory abnormality detectable in two.

In summary, there was evidence from either history or examination of some sensory abnormality in all except three patients. However, in none was this severe. The most marked abnormality of superficial sensation was subjective alteration to touch or pin prick, with objective loss in only one. Vibration sensation was preserved in all and position sense was defective for fine movements of the terminal phalanges only. Loss of stereognosis was, however, marked in some, and was the only sensory abnormality in two patients.

ELECTROPHYSIOLOGICAL STUDIES A Medelec MS4 electromyograph was used for recording nerve action potentials. The frequency response at the amplifier gains used in this study was 16 to $1,000 \mathrm{~Hz}$ at $-3 \mathrm{~dB}$. The constant voltage stimulator had a voltage range of up to 200 volts and fixed stimulus duration of $0.3 \mathrm{msec}$.

Subjects were examined in a warm room. Limb temperature was not recorded. In most instances prior warming of the limbs in hot water was considered unnecessary and this was done only occasionally when the limbs felt cold to touch.

In the upper limbs sensory nerve action potentials were recorded from the median nerve at the wrist through saddle electrodes $4 \mathrm{~cm}$ apart on the skin as described by Dawson (1956). Supramaximal shocks were applied through ring electrodes round the index finger. The peak-to-peak amplitude of the potential was measured. Latency was measured to the onset of the negative phase of the action potential, and conduction velocity calculated. This gives an estimate of conduction in the most rapidly conducting fibres, the delay in initiation of the impulse being insignificant (Gilliatt et al., 1965).

In order to record the mixed nerve action potentials from the lateral popliteal nerve in the leg, the nerve was stimulated at the ankle. The action potential was recorded through needle electrodes, $4 \mathrm{~cm}$ apart, placed beside the lateral popliteal nerve at the neck of the fibula, as described by Gilliatt et al. (1961). Peak-to-peak amplitude and latency to peak of the potential were measured. For small potentials latency can be more accurately measured to the peak than onset of the potential. Although velocity calculated from this latency is difficult to relate to any particular fibres in the nerve trunk, it is a parameter which has been frequently used in other studies. It enabled comparisons to be made with the control data of Gilliatt et al. (1961).

SUBJECTS Upper limbs Sensory nerve action potentials were recorded from the median nerve at the wrist in all 19 patients. To provide control values, 20 healthy English subjects aged 16-52 years, were examined under similar conditions and using the same apparatus.

Lower limbs Conduction studies were carried out in the legs of 10 patients. These included two of the patients with severe mental disturbances, and eight others with the most marked sensory abnormalities clinically. Control values obtained by Gilliatt et al. (1961) from 20 healthy subjects aged 18-49 years were used for comparison with the patients.

\section{RESULTS}

UPPER LIMBS Sensory nerve action potentials were recorded from the median nerve at the wrist in 19 patients and 20 control subjects. Values for conduction velocity and amplitude of the potential in individual subjects are shown in Fig. 1. It can be seen that the values for the patients fell within the control range.

For statistical analysis of the results, adults and children were considered separately, and the results are shown in Table 5 . Conduction velocity in children has reached the adult range by the age of 5 years (Gamstorp and Shelburne, 1965)

TABLE 5

MEAN VALUES AND STANDARD DEVIATIONS FOR VELOCITY AND AMPLITUDE OF MEDIAN SENSORY NERVE ACTION POTENTIAL RECORDED AT WRIST

\begin{tabular}{lcccc}
\hline & $\begin{array}{c}\text { Subjects } \\
(\text { no. })\end{array}$ & $\begin{array}{c}\text { Age }(y r) \\
(\text { range })\end{array}$ & $\begin{array}{c}\text { Onset velocity } \\
(\mathrm{m} / \mathrm{sec})\end{array}$ & $\begin{array}{c}\text { Amplitude } \\
(\mu \mathrm{V})\end{array}$ \\
\hline $\mathrm{Me} \mathrm{Hg}$ & 11 & $\begin{array}{c}29 \cdot 2 \\
(15-55)\end{array}$ & $58 \cdot 1 \pm 7 \cdot 0$ & $21 \cdot 5 \pm 8 \cdot 1$ \\
$\mathrm{Me} \mathrm{Hg}$ & 8 & $\begin{array}{c}10 \cdot 1 \\
(5-14)\end{array}$ & $54 \cdot 5 \pm 4 \cdot 1$ & $28 \cdot 8 \pm 6 \cdot 7$ \\
Control & 20 & $\begin{array}{c}27 \cdot 4 \\
(16-52)\end{array}$ & $56 \cdot 2 \pm 5 \cdot 1$ & $26 \cdot 6 \pm 10 \cdot 6$ \\
\end{tabular}



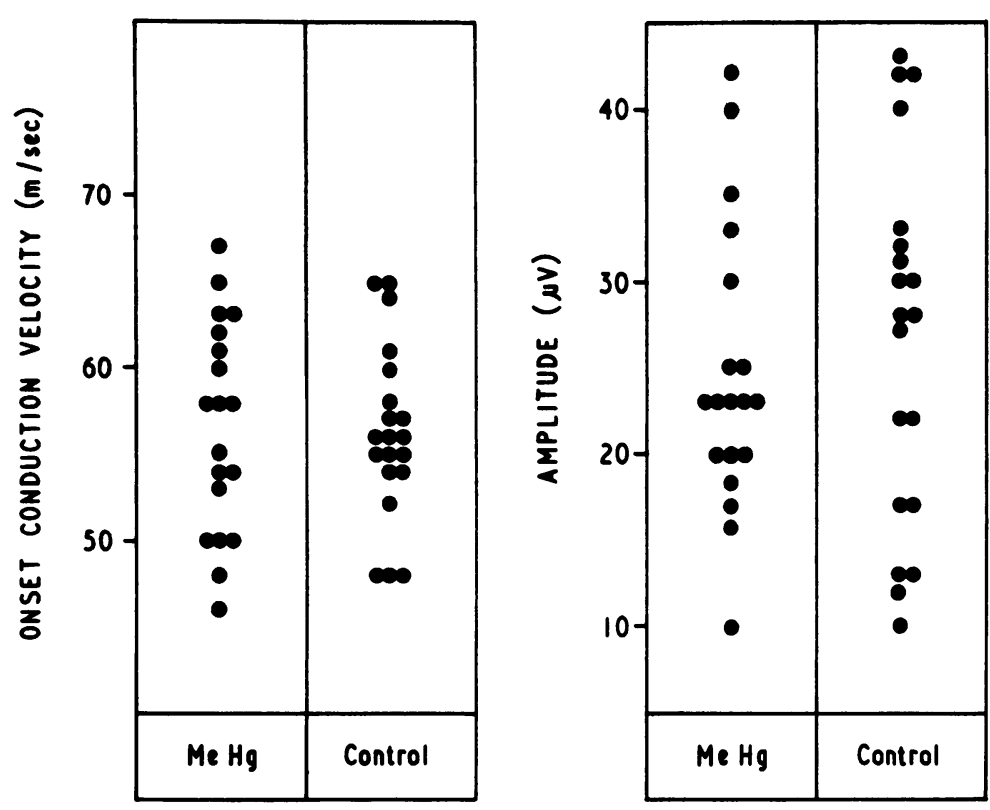

FIG. 1. Conduction velocity and peak-to-peak amplitude of median sensory nerve action potential recorded at wrist after stimulation at base of index finger.
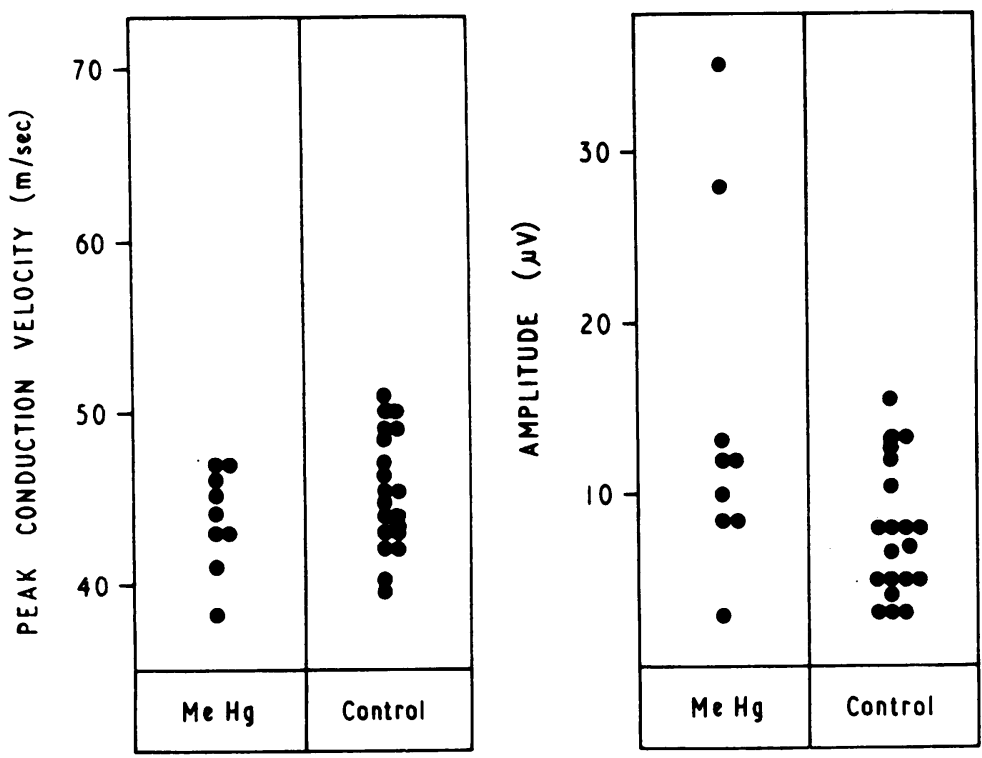

FIG. 2. Conduction velocity and peak-to-peak amplitude of lateral popliteal nerve action potential at head of fibula following stimulation at ankle. Control values from Gilliatt et al. (1961).

but no direct comparisons have been made of mean values for children and adults. The amplitude of median sensory nerve action potentials recorded at the wrist is approximately $5 \mu \mathrm{V}$ greater in children aged $4-12$ years than in young adults (Dunn, personal communication).

It can be seen from Table 5 that the mean values for velocity and amplitude for children and adult patients were very similar to those 
from control subjects and none of the differences were significant.

LOWER LIMBS In nine patients mixed nerve action potentials were recorded from the lateral popliteal nerve at the head of the fibula after stimulation at the ankle. In Fig. 2 individual results are compared with control values for 20 subjects examined by Gilliatt et al. (1961). It can be seen that no smaller potentials were recorded from the patients than from the control subjects, but that considerably larger potentials were recorded in two patients. These two patients were aged 5 and 9 years, and the large potentials may be related to their age. No control data are available for action potential amplitude in the lower limbs in children, but it is possible that potentials are larger in healthy children than adults, as found by Dunn (personal communication) in the upper limbs.

In Table 6 mean values for velocity and amplitude are shown for adult patients, age

\section{TABLE 6}

MEAN VALUES AND STANDARD DEVIATIONS FOR VELOCITY AND AMPLITUDE OF LATERAL POPLITEAL NERVE ACTION POTENTIALS*

\begin{tabular}{lcccc}
\hline & $\begin{array}{c}\text { Subjects } \\
(\text { no. })\end{array}$ & $\begin{array}{c}\text { Age }(\mathrm{yr}) \\
(\text { range })\end{array}$ & $\begin{array}{c}\text { Peak velocity } \\
(\mathrm{m} / \mathrm{sec})\end{array}$ & $\begin{array}{c}\text { Amplitude } \\
(\mu \mathrm{V})\end{array}$ \\
\hline $\mathrm{Me} \mathrm{Hg}$ & 5 & $\begin{array}{c}29.0 \\
(15-50)\end{array}$ & $44 \cdot 2 \pm 2.4$ & $8.8 \pm 3.7$ \\
$\mathrm{Me} \mathrm{Hg}$ & 4 & $\begin{array}{c}9.5 \\
(5-14) \\
34.8\end{array}$ & $43.3 \pm 3.9$ & $21.5 \pm 12.0$ \\
Control* & 20 & $\begin{array}{c}45.4 \pm 3.4 \\
(18-49)\end{array}$ & $7.8 \pm 3.9$ \\
\hline
\end{tabular}

* Control results are from Gilliatt et al. (1961).

matched control subjects and children. There was no statistical difference for velocity or amplitude between the adult patients and age matched control subjects. It can be seen that the velocity in children was also comparable. A possible reason for the larger amplitude found in children has already been mentioned.

In one other patient no nerve action potential could be recorded from the lateral popliteal nerve. In this patient no muscle potential could be recorded from extensor digitorum brevis on stimulation of the lateral popliteal nerve. He had been bed ridden, restless, and confused for three months, and it is possible that he had sustained a coincidental pressure lesion of his lateral popliteal nerve.

\section{DISCUSSION}

The patients described here show the features of organic mercury toxicity described by Hunter et al. (1940). Cerebellar involvement produced the most severe disability. The visual and sensory changes had much less effect on function, since central vision was usually normal and sensory loss was mild. The pyramidal system was spared in all except the most severe cases.

Normal central acuity with grossly constricted visual fields is an unusual defect to be produced by a cortical lesion, except when of vascular origin. Pathological changes have been described in the occipital cortex, with sparing of the occipital pole subserving macular vision. There is no pathological evidence of vascular occlusion (Hunter and Russell, 1954). Nor is there any clinical evidence for a peripheral lesion. The underlying factors responsible for the site of damage, however, remain obscure.

A number of different types of involuntary movement have been described previously in organic mercury poisoning (Tokuomi, 1968; Snyder, 1972), chorea and athetosis occurring most commonly. Myoclonus has been reported occasionally (Kurland et al., 1960; Shiraki and Takeuchi, 1971). In the present study chorea and athetosis were not seen, but two of the more severely affected patients had frequent myoclonic jerks.

There are several clinical features of the sensory abnormalities which are more suggestive of damage to the central rather than peripheral nervous system. Preservation of tendon reflexes suggests that the largest myelinated fibres were spared. Preservation of vibration sensation in conjunction with loss of position sense and astereognosis is more often seen in central than peripheral lesions. In diabetic neuropathy, for example, vibration appreciation is commonly the first modality of sensation to be affected. Astereognosis as the sole sensory abnormality, such as was seen in two patients, rarely occurs in peripheral neuropathy. 
Pathological changes have been described in the parietal cortex after organic mercury poisoning (Hunter and Russell, 1954; Takeuchi, 1968). It has previously been suggested that there might be two components to the sensory lesion, one central, and the other peripheral and reversible (Shiraki and Takeuchi, 1971). The electrophysiological findings do not support this interpretation. In the present group of subjects both amplitude and velocity of sensory nerve action potentials were normal. Thus, despite persistent sensory symptoms and signs there was no evidence of gross damage to peripheral nerve fibres. It may be concluded from this study that the presence of sensory peripheral neuropathy in organic mercury intoxication in man is still unsubstantiated.

We would like to thank the Scientific Committee on mercury poisoning in Iraq (chairman, Professor F. Bakir) for allowing us to conduct the research work; and the following members of the clinical committee for permission to test the patients under their care: Professor Laman Amin-Zaki, Professor T. Hamdi, Dr. S. Elhassani, Dr. H. Abbasi, and Dr. J. Kuwaiti. We are also grateful to Professor R. W. Gilliatt for his helpful comments.

\section{REFERENCES}

Bakir, F. et al. (1973). Methyl mercury poisoning in Iraq: an inter-university report. Science, 181, 230-241.

Borg, K., Erne, K., Hanko, E., and Wanntorp, H. (1970). Experimental secondary methyl mercury poisoning in the goshawk (Accipiter G. Gentilis L.). Environmental Pollution, 1, 91-104.

Borg, K., Wanntorp, H., Erne, K., and Hanko, E. (1969). Alkyl mercury poisoning in terrestrial Swedish wildlife. Viltrevy, 6, 299-379.

Cavanagh, J. B., and Chen, F. C. K. (1971). The effects of methyl-mercury-dicyandiamide on the peripheral nerves and spinal cord of rats. Acta Neuropathologica, 19, 208215.

Damluji, S. (1962). Mercurial poisoning with the fungicide
Granosan M. Journal of the Faculty of Medicine, Baghdad, 4, 83-103.

Damluji, S. F., and Tikriti, S. (1972). Mercury poisoning from wheat. British Medical Journal, 1, 804.

Dawson, G. D. (1956). The relative excitability and conduction velocity of sensory and motor nerve fibres in man. Journal of Physiology, 131, 436-451.

Expert Group on Methyl Mercury in Fish (1971). Methyl Mercury in Fish. A Toxicologic Epidemiologic Evaluation of Risks. Nordisk Hygienisk Tidskrift, Suppl. 4.

Gamstorp, I., and Shelburne, S. A., Jr. (1965). Peripheral sensory conduction in ulnar and median nerves of normal infants, children, and adolescents. Acta Paediatrica Scandinavica, 54, 309-313.

Gilliatt, R. W., Goodman, H. V., and Willison, R. G. (1961). The recording of lateral popliteal nerve action potentials in man. Journal of Neurology, Neurosurgery, and Psychiatry, 24, 305-318.

Gilliatt, R. W., Melville, I. D., Velate, A. S., and Willison, R. G. (1965). A study of normal nerve action potentials using an averaging technique (barrier grid storage tube). Journal of Neurology, Neurosurgery, and Psychiatry, 28, 191-200.

Hanko, E., Erne, K., Wanntorp, H., and Borg, K. (1970). Poisoning in ferrets by tissues of alkyl mercury-fed chickens. Acta Veterinaria Scandinavica, 11, 268-282.

Hunter, D., Bomford, R. R., and Russell, D. S. (1940). Poisoning by methyl mercury compounds. Quarterly Journal of Medicine, 9, 193-213.

Hunter, D., and Russell, D. S. (1954). Focal cerebral and cerebellar atrophy in a human subject due to organic mercury compounds. Journal of Neurology, Neurosurgery, and Psychiatry, 17, 235-241.

Jalili, M. A., and Abbasi, A. H. (1961). Poisoning by ethyl mercury toluene sulphonanilide. British Journal of Industrial Medicine, 18, 303-308.

Kurland, L. T., Faro, S. N., and Siedler, H. (1960). Minamata disease. World Neurology, 1, 370-395.

Miyakawa, T., Deshimaru, M., Sumiyoshi, S., Teraoka, A., Udo, N., Hattori, E., and Tatetsu, S. (1970). Experimental organic mercury poisoning-pathological changes in peripheral nerves. Acta Neuropathologica, 15, 45-55.

Shiraki, H., and Takeuchi, T. (1971). Minamata disease. In Pathology of the Nervous System, Vol. 2, pp. 1651-1665. Edited by J. Minckler. McGraw-Hill: New York.

Snyder, R. D. (1972). The involuntary movements of chronic mercury poisoning. Archives of Neurology (Chic.), 26, 379381.

Takeuchi, T. (1968). Pathology of Minamata disease. In Minamata Disease, pp. 141-228. Edited by M. Kutsuna. Kumamoto University: Japan.

Tokuomi, H. (1968). Minamata disease in human adult. In Minamata Disease, pp. 37-72. Edited by M. Kutsuna. Kumamoto University: Japan.

Addendum
Since this study was performed, further electrophysiological investigations have been carried out on subjects exposed to methyl mercury, some of whom are included in the present report (Von Berg and Rustam, to be published). Similar results were obtained for measurements of conduction velocity. 